\title{
A randomised, open label comparative study of hydroxychloroquine with betamethasone oral mini pulse in the management of patients with alopecia areata
}

\author{
Jeyasudha Jambusayee*, Kulur Mukhyaprana Sudha
}

Department of Pharmacology, Madras Medical College, Chennai, Tamil Nadu, India

Received: 14 December 2020

Accepted: 11 January 2021

\section{*Correspondence:}

Dr. Jeyasudha Jambusayee,

Email: jeysuj@gmail.com

Copyright: (C) the author(s), publisher and licensee Medip Academy. This is an open-access article distributed under the terms of the Creative Commons Attribution Non-Commercial License, which permits unrestricted non-commercial use, distribution, and reproduction in any medium, provided the original work is properly cited.

\section{ABSTRACT}

Background: Alopecia areata is an autoimmune disorder causing patchy hair loss on scalp and other parts of the body and leading to poor self-esteem and anxiety in patients. Treatment with topical or systemic drugs like steroids or other immunosuppressants is associated with adverse effects. Hydroxychloroquine is an antimalarial drug, with $\mathrm{T}$ cell modulating function. This study was undertaken to assess the safety, efficacy and tolerability of Hydroxychloroquine in Alopecia areata compared to betamethasone oral mini pulse (OMP) therapy.

Methods: 60 patients with alopecia areata were randomized into two groups of 30 each. Control group received tab. betamethasone $5 \mathrm{mg} /$ day on two consecutive days of week for 12 weeks and Study group received tab. hydroxychloroquine $200 \mathrm{mg} /$ day for 12 weeks. They were followed-up for further 12 weeks. Scale of alopecia tool, dermatology life quality index and global assessment at baseline, 12 weeks and 24 weeks were used to assess the outcome.

Results: 94 patients were screened and 60 patients were included. All patients completed the study. At the end of 12 weeks, there was a statistically significant reduction in SALT and DLQI scores in both control and study groups. But at the end of 24 weeks, the study group showed an increase in the scores. Relapses were more in the study group. No significant difference in the incidence of adverse events was noted between the two groups.

Conclusions: Hydroxychloroquine $200 \mathrm{mg}$ /day is less efficacious in the management of alopecia areata in comparison to betamethasone oral mini pulse therapy.

Keywords: Betamethasone oral mini pulse, Hydroxychloroquine, Alopecia areata

\section{INTRODUCTION}

Alopecia areata is a chronic disease affecting the hair follicle and the nails. Both genetic and environmental factors play a role in the pathogenesis of the disease. The incidence is $0.1-0.2 \%$ with a $1.7 \%$ lifetime risk of developing the disease. In India, the incidence of the disease is $0.7 \%$ in the dermatology out patient department. $^{1} \quad$ Alopecia areata is associated with autoimmune diseases like myxedema and pernicious anaemia. $^{2}$
Any age and both sexes may be affected. The usual presentation is an asymptomatic patch of hair loss, on the scalp or any other hairy part of the body including eyebrows and eyelashes. Severe cases are characterized by loss of hair on the entire scalp (alopecia totalis) or even the whole of the body (alopecia universalis). ${ }^{3}$ The patches are devoid of redness, itching, scaling or follicular changes. Individual patches may expand circumferentially, coalesce and form a large patch. Nail changes are seen in 10-15\% of cases of alopecia areata, of which the most common finding is a fine, stippled pitting of the nails. ${ }^{4}$ Presence of nail changes indicates a severe disease. 
In early stages, histopathology shows a perifollicular and intrafollicular inflammatory cell infiltrate surrounding the anagen follicles composed of activated CD4 T lymphocytes and an admixture of macrophages and Langerhans' cells. This is termed as 'swarm of bees' appearance..$^{5}$ This autoimmune process is thought to lead to truncation of the anagen (growth) phase and precipitation of hair follicles into telogen(resting) phase. Alopecia areata is associated with considerable psychiatric morbidity. Patchy loss of hair leads to poor self-esteem and impairment in the quality of life as evidenced by reduced sports and recreational activities and diminished sexual drive. ${ }^{6}$ The lifetime prevalence rates of major depression (39\%) and generalized anxiety disorder (39\%) in these patients were high.

Treatment of alopecia areata ranges from simple reassurance for mild cases to cosmetic camouflage for severe treatment resistant cases. Majority of patients need topical or systemic agents. Topical agents include irritants, topical steroids, Minoxidil and contact sensitizers. Contact sensitizers are allergens which on repeated application, induce a severe allergic contact dermatitis. This causes immunomodulation and gradual regrowth of hair. ${ }^{7}$ Topical agents are useful only in localized disease.

Systemic agents used in severe cases of alopecia areata like alopecia totalis and alopecia universalis. The mainstay of systemic therapy is corticosteroids for their immunosuppressive and anti-inflammatory action. Others include immunosuppressants, biologicals phototherapy. Steroids are administered as pulse therapy which refers to administration of supra-pharmacologic doses of drugs in intermittent manner. ${ }^{8}$ Oral betamethasone given at a dose of $10 \mathrm{mg}$ once weekly is termed as mini pulse. It is used in dermatoses like vitiligo, lichen planus and alopecia areata with variable success rates. $10 \mathrm{mg}$ of betamethasone maybe split into 2 equal doses and given as $5 \mathrm{mg} /$ day on 2 consecutive days of a week.

All these available modalities of treatment are fraught with significant adverse effects in the long term. This lowers the quality of life, makes the patients poorly compliant to therapy and worsens the outcome of the disease.

Hydroxychloroquine is an antimalarial drug, with $\mathrm{T}$ cell modulating function. It is used with varying degrees of success in rheumatoid arthritis systemic lupus erythematosus and skin conditions like frontal fibrosing alopecia and Lichen planopilaris. It is also used as a systemic sunscreen in photo dermatoses. There are case reports of successful use of hydroxychloroquine in severe and treatment resistant cases of Alopecia areata from the western countries, but no data are available from India. ${ }^{10}$

Hence this study is undertaken to assess the safety and efficacy of Hydroxychloroquine in alopecia areata and its tolerability in Indian patients. It is compared with OMP therapy which is the standard treatment given in this condition.

\section{METHODS}

The study was conducted after obtaining the approval from institutional ethics committee, Madras medical college and it was done in accordance with good clinical practice (GCP) guidelines.

Patients diagnosed with alopecia areata attending the outpatient department, department of dermatology, Madras medical college and Rajiv Gandhi government general hospital, were explained about the study purpose, procedure and benefits of the study. Written informed consent was obtained from those subjects who are willing to participate in the study in the prescribed format in regional language. The demographic details of the patients were obtained and recorded.

The subjects were screened by complete medical history, clinical examination, ophthalmic examination and laboratory investigations. Those who fulfilled the selection criteria were enrolled. Adult patients of both sexes, who presented with alopecia areata of the scalp region and those willing to give written informed consent were included. Pregnant women and lactating mothers, patients with known hypersensitivity to hydroxychloroquine, those with visual symptoms or evidence of retinal damage, those who have participated in another clinical study in last 3 months and patients with diabetes mellitus, hypertension, HIV infection or any other chronic systemic illness of liver, kidney, gastrointestinal tract, heart etc. were excluded.

The enrolled patients were randomized by simple randomization into either control group or study group and received the respective therapy. The control group received tab. betamethasone $5 \mathrm{mg}$ on two consecutive days of the week for 12 weeks. The Study group received tab. hydroxychloroquine $200 \mathrm{mg} /$ day for 12 weeks. After the treatment period of 12 weeks, the drugs were stopped and the patients were followed up for a further 12 weeks.

\section{Assessment parameters}

Our primary end point was to assess the percentage regrowth of hair in each quadrant of scalp as estimated using severity of alopecia tool.

Our secondary end point was to look for- Improvement in dermatology life quality index. Improvement in global assessment score.

\section{Severity of alopecia tool ${ }^{11}$}

SALT score is useful for quantitative assessment of scalp hair loss. The entire scalp is divided into 4 parts based on the surface area, vertex (40\%-0.4), occipital (24\%-0.24), right profile (18\%-0.18), and left profile (18\%-0.18).

Percentage of hair loss in each area is determined independently and is multiplied by the percentage of scalp covered in that area of the scalp, and summing the products 
of each area gives the SALT score. SALT score is easily reproducible and validated. However, it does not include hair pigmentation and nail involvement. Also, the loss of hair in other areas of the body cannot be assessed.

\section{Dermatology life quality index ${ }^{12}$}

The dermatology life quality index is the first dermatology-specific quality of life questionnaire. The DLQI consists of 10 questions concerning symptoms and feelings, daily activities, leisure, work, and school, personal relationships and treatment over the last oneweek period. Each question is scored from 0 to 3 and the scores summed, giving a range from 0 (no impairment of life quality) to 30 (maximum impairment). It is designed to be used in adults.

\section{Global assessment}

The treatment outcome and satisfaction level are measured using global assessment. The score is given as below excellent (4), very good (3), good (2), satisfactory (1), no response (0).

The score is independently given by the physician and patient and the sum is obtained.

\section{Investigations}

The following laboratory investigations were performed in the patients on screening and at the end of treatment period. Hematology-hemoglobin, total leucocyte count, blood glucose, blood urea, serum creatinine, liver function test (total bilirubin, SGOT, SGPT), ophthalmic examination.

The patients were followed up every 4 weeks during the treatment period and the post treatment period.

\section{Adverse events}

Patients were advised to report the occurrence of any adverse drug events, other illnesses or intake of other drugs. Any adverse event reported by the patient or observed by the physician during the study was recorded. The onset of the event, causal relationship to the study drug and treatment given were recorded.

\section{Withdrawal}

During the study period the subject was allowed to withdraw his/her voluntary consent and opt out of study. Similarly, at the discretion of the investigator, the subjects were withdrawn from the study if any serious adverse events occurred.

\section{Statistical analysis}

The obtained data was analyzed statistically using SPSS software version 21.0. Distribution of age was analyzed by
Mean \pm SD. The differences within the groups in SALT score, DLQI score and GA were analyzed using students paired t-test. Similarly, the differences between the control and test groups were analyzed using independent t-test. For the laboratory investigations, the differences within the groups before and after treatment were analyzed using student's paired t- test. $\mathrm{P}$ value $<0.05$ was considered to be statistically significant.

\section{RESULTS}

Basic demographic profile showed no significant difference in the mean age and sex distribution in both the control and the study groups (Table 1). The average age in both the groups was 30 . Gender distribution was found equal in both the groups (males-18 and females-12 in control and study groups). The number of patches and the mean duration of illness were also found to be comparable in both control and study groups.

Table 1: Base line parameters.

\begin{tabular}{|llllll|}
\hline \multirow{2}{*}{ Parameter } & $\begin{array}{l}\text { Control } \\
\text { group }\end{array}$ & \multicolumn{3}{c}{ Study group } & P \\
\cline { 2 - 5 } & Mean & SD & Mean & SD & \\
\hline $\begin{array}{l}\text { Age of patient } \\
\text { (years) }\end{array}$ & 30.3 & 8.77 & 30.5 & 7.83 & 0.673 \\
\hline No. of patches & 2.70 & - & 2.67 & - & 0.915 \\
\hline $\begin{array}{l}\text { Duration } \\
\text { (months) }\end{array}$ & 5.42 & 3.24 & 5.87 & 3.80 & 0.62 \\
\hline Salt score & 21.50 & 11.6 & 22.37 & 9.08 & 0.75 \\
\hline DLQI score & 20.07 & 3.21 & 20.53 & 2.66 & 0.54 \\
\hline $\begin{array}{l}\text { Global } \\
\text { assessment }\end{array}$ & 1.57 & 1.14 & 1.37 & 1.07 & 0.49 \\
\hline
\end{tabular}

Table 2: Gender distribution.

\begin{tabular}{|lllllll|}
\hline Group & Male & \multicolumn{3}{c|}{ Female } & \multicolumn{2}{c|}{ Total } \\
\hline Control & N & \% & N & \% & N & \% \\
\hline Study & 18 & 60 & 12 & 40 & 30 & 100 \\
\hline
\end{tabular}

Table 3: Scale of alopecia tool.

\begin{tabular}{|llllll|}
\hline Duration & \multicolumn{2}{l}{ Control group } & \multicolumn{2}{l|}{ Study group } & P \\
\cline { 2 - 6 } (Weeks) & Mean & SD & Mean & SD & value \\
\hline $\mathbf{0}$ & 21.50 & 11.64 & 22.37 & 9.08 & 0.75 \\
\hline $\mathbf{4}$ & 19.80 & 10.31 & 22.23 & 8.79 & 0.33 \\
\hline $\mathbf{8}$ & 13.77 & 6.60 & 16.6 & 6.90 & 0.10 \\
\hline $\mathbf{1 2}$ & 9.17 & 4.94 & 9.83 & 4.71 & 0.59 \\
\hline $\mathbf{1 6}$ & 8.13 & 4.45 & 9.80 & 4.41 & 0.15 \\
\hline $\mathbf{2 0}$ & 7.30 & 4.26 & 10.0 & 4.66 & 0.02 \\
\hline $\mathbf{2 4}$ & 7.47 & 4.48 & 10.33 & 5.38 & 0.03 \\
\hline
\end{tabular}

In this study, the scale of alopecia tool (SALT) score showed a statistically significant decrease $(p<0.01)$ at the end of 12 weeks in both the control and study groups (Table 3 and Figure 1). This is in agreement with the case series of successful treatment of alopecia areata with tab. 
hydroxychloroquine. ${ }^{13,14}$ Comparison between the groups showed that the improvement was similar in both groups during the treatment period, but in the follow up period the control group treated with Betamethasone maintained the improvement. The study group receiving hydroxychloroquine did not maintain the benefits of treatment after 16 weeks.

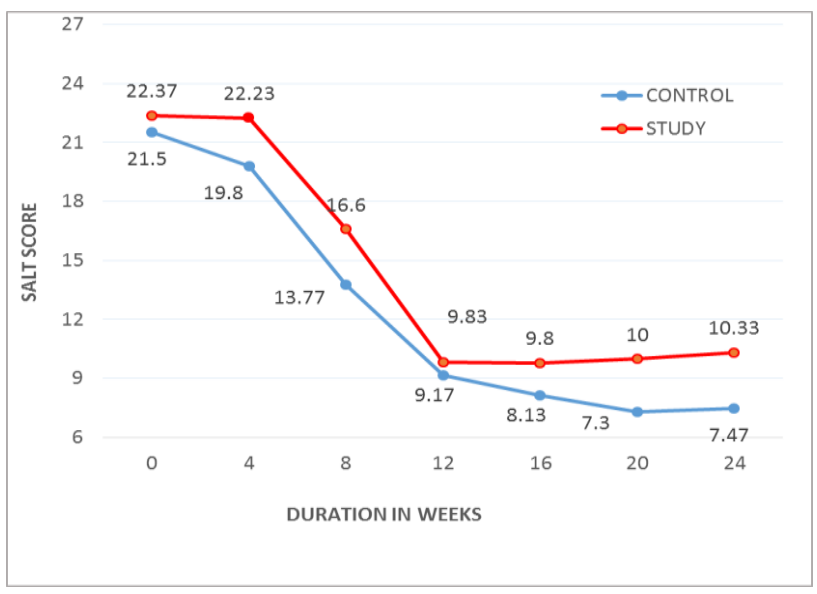

Figure 1: Scale of alopecia tool.

Table 4: Dermatology life quality index.

\begin{tabular}{|llllll|}
\hline $\begin{array}{l}\text { Duration } \\
\text { (Weeks) }\end{array}$ & \multicolumn{2}{l}{ Control group } & \multicolumn{2}{l|}{ Study group } & P \\
\hline $\mathbf{0}$ & 20.07 & 3.21 & 20.53 & 2.66 & 0.54 \\
\hline $\mathbf{4}$ & 18.53 & 3.13 & 18.87 & 2.40 & 0.65 \\
\hline $\mathbf{8}$ & 15.10 & 2.45 & 15.03 & 2.57 & 0.92 \\
\hline $\mathbf{1 2}$ & 11.90 & 2.63 & 12.83 & 2.88 & 0.19 \\
\hline $\mathbf{1 6}$ & 10.80 & 2.66 & 12.23 & 2.70 & 0.04 \\
\hline $\mathbf{2 0}$ & 11.13 & 2.84 & 13.03 & 3.03 & 0.02 \\
\hline $\mathbf{2 4}$ & 11.53 & 3.41 & 13.93 & 3.13 & 0.006 \\
\hline
\end{tabular}

Table 5: Global assessment.

\begin{tabular}{|llllll|}
\hline $\begin{array}{l}\text { Duration } \\
\text { (Weeks) }\end{array}$ & \multicolumn{2}{l}{ Control group } & \multicolumn{2}{l}{ Study group } & P \\
\hline $\mathbf{0}$ & 1.57 & 1.14 & 1.37 & 1.07 & 0.49 \\
\hline $\mathbf{4}$ & 2.7 & 0.92 & 2.6 & 0.81 & 0.66 \\
\hline $\mathbf{8}$ & 4.93 & 0.79 & 4.67 & 0.88 & 0.22 \\
\hline $\mathbf{1 2}$ & 7.03 & 0.77 & 6.7 & 0.83 & 0.11 \\
\hline $\mathbf{1 6}$ & 7.23 & 0.73 & 6.8 & 0.99 & 0.06 \\
\hline $\mathbf{2 0}$ & 6.43 & 1.14 & 5.77 & 1.33 & 0.04 \\
\hline $\mathbf{2 4}$ & 6.33 & 1.21 & 5.6 & 1.38 & 0.03 \\
\hline
\end{tabular}

Table 6: Adverse events.

\begin{tabular}{|lll|}
\hline Adverse events & Control group & Study group \\
\hline Nausea & 1 & 2 \\
\hline Vomiting & 2 & 2 \\
\hline Abdomen pain & 3 & 4 \\
\hline Muscle pain & 2 & 1 \\
\hline Head ache & 1 & 1 \\
\hline Dizziness & 1 & 1 \\
\hline
\end{tabular}

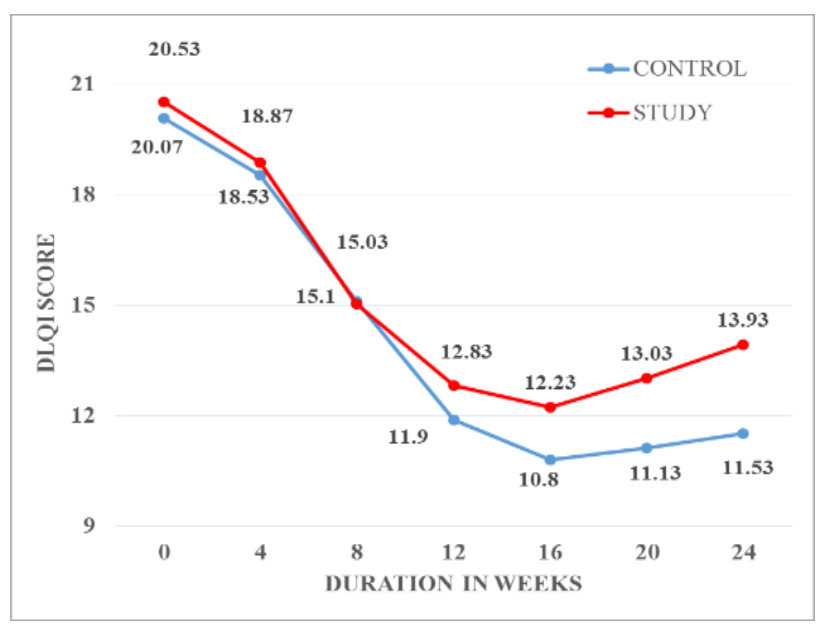

Figure 2: Dermatology life quality index.

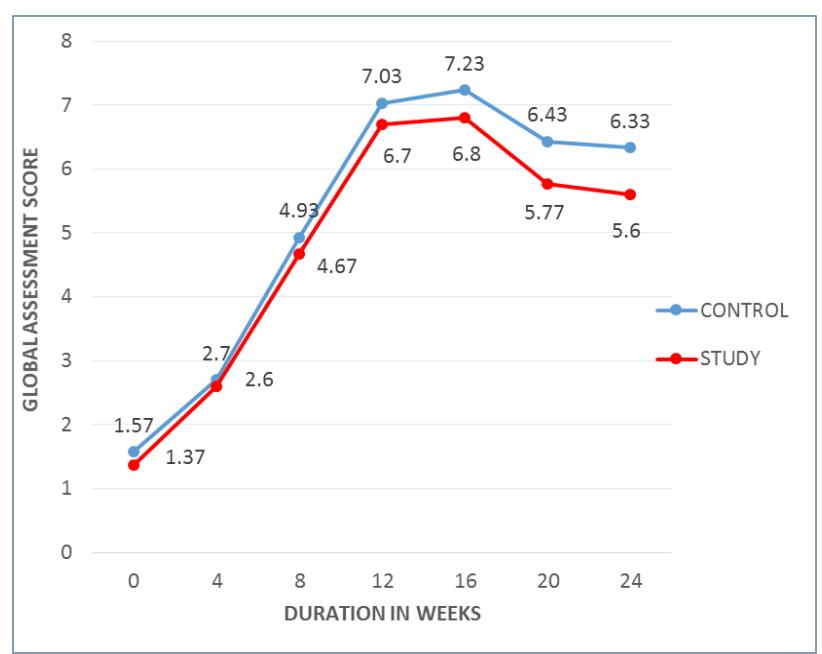

Figure 3: Global assessment.

Table 7: Laboratory investigations (control group).

\begin{tabular}{|llll|}
\hline & \multicolumn{2}{l}{ Control group } & $\mathbf{P}$ \\
& Baseline & $\begin{array}{l}\mathbf{1 2} \\
\text { weeks }\end{array}$ & value \\
\hline Hemoglobin (gm\%) & 11.68 & 11.7 & 0.966 \\
\hline $\begin{array}{l}\text { Total WBC count } \\
\text { (cells/mm }\end{array}$ & 7423 & 7520 & 0.838 \\
\hline Blood sugar (mg/dl) & 92.13 & 88.53 & 0.189 \\
\hline Blood urea (mg/dl) & 25.03 & 25.8 & 0.535 \\
\hline $\begin{array}{l}\text { Serum creatinine } \\
\text { (mg/dl) }\end{array}$ & 0.98 & 0.94 & 0.33 \\
\hline $\begin{array}{l}\text { Serum bilirubin } \\
\text { (mg/dl) }\end{array}$ & 0.89 & 0.82 & 0.12 \\
\hline SGOT (IU/) & 29.6 & 29.4 & 0.89 \\
\hline SGPT (IU/l) & 28.9 & 29.7 & 0.49 \\
\hline
\end{tabular}

The DLQI and global assessment scores showed changes similar to the SALT score (Table 4 and 5, Figure 2 and 3). Both the groups of patients showed a statistically significant improvement in the quality of life and overall treatment response during the study period. But after 
stopping the treatment, both groups of patients again showed a reduction in response around 16 to 20 weeks which is more pronounced in the study group. No significant difference was noted between the groups at the baseline and end of study period.

Table 8: Laboratory investigations (study group).

\begin{tabular}{|c|c|c|c|}
\hline \multirow[b]{2}{*}{ Investigations } & \multicolumn{2}{|c|}{ Study group } & \multirow[b]{2}{*}{$\begin{array}{l}P \\
\text { value }\end{array}$} \\
\hline & Baseline & $\begin{array}{l}12 \\
\text { weeks }\end{array}$ & \\
\hline Hemoglobin (gm\%) & 12.03 & 11.95 & 0.87 \\
\hline $\begin{array}{l}\text { Total WBC count } \\
\left(\text { cells } / \mathbf{m m}^{3}\right)\end{array}$ & 7847 & 7070 & 0.11 \\
\hline Blood sugar (mg/dl) & 91.67 & 88.67 & 0.29 \\
\hline Blood urea (mg/dl) & 24.23 & 25.93 & 0.16 \\
\hline $\begin{array}{l}\text { Serum creatinine } \\
(\mathrm{mg} / \mathrm{dl})\end{array}$ & 0.99 & 0.96 & 0.60 \\
\hline $\begin{array}{l}\text { Serum bilirubin } \\
(\mathrm{mg} / \mathrm{dl})\end{array}$ & 0.89 & 0.86 & 0.46 \\
\hline SGOT (IU/I) & 29.67 & 29.20 & 0.73 \\
\hline SGPT (IU/I) & 28.10 & 29.37 & 0.31 \\
\hline
\end{tabular}

This study shows that tab hydroxychloroquine $200 \mathrm{mg}$ /day is slightly less efficacious in the management of patients with alopecia areata when compared to betamethasone OMP. No statistically significant difference in the laboratory investigation were noted in the control and study groups at the end of treatment period when compared with the baseline using paired t-test (Table 6 and 7).

\section{DISCUSSION}

No serious adverse events were reported in this study (Table 6). Abdomen pain and vomiting which were the most common adverse events reported by Khaitan et al for betamethasone were also commonly noted in this study. ${ }^{15}$ Other adverse events noted were nausea, muscle pain, dizziness and headache. The patients were asked to take the drugs after food. Other adverse events were managed symptomatically. No cases of retinopathy were seen in the patients treated with hydroxychloroquine. No significant difference in the incidence of adverse events is noted between the two groups. During the post treatment period, 2 patients from the Betamethasone group and 5 patients from the hydroxychloroquine group reported with a relapse of their condition.

This study had a 12 weeks treatment period which is an insufficient time to study the course and treatment response of a chronic disease. This is an open label study and no blinding was done. The assessment parameters were more subjective and prone for observer bias. These factors may be considered as the limitations of this study. Further long duration, placebo controlled and blinded clinical trials will ascertain the role and usefulness of hydroxychloroquine in alopecia areata.

\section{CONCLUSION}

From this study, we conclude that, hydroxychloroquine $200 \mathrm{mg} /$ day is less efficacious compared to betamethasone OMP in the management of patients with Alopecia areata. It may still be useful in those patients in whom systemic steroids are contraindicated. Hydroxychloroquine 200 $\mathrm{mg} /$ day is well tolerated and no serious adverse events were reported.

\section{Funding: No funding sources}

Conflict of interest: None declared

Ethical approval: The study was approved by the Institutional Ethics Committee

\section{REFERENCES}

1. Seetharam KA. Alopecia areata: An update. Indian J Dermatol. 2013;79:563-75.

2. Cunliffe WJ, Hall R, Stevenson CJ, Weightman D. Alopecia areata, thyroid disease and autoimmunity. Br J Dermatol. 1969;81:877-81.

3. Bolognia JL, Jorizzo JL, Schaffer JV, Callen JP, Cerroni L, Heymann WR. Dermatology, Third Edition, Northwestern university, Northwestern Scholars. 2012;1:1100.

4. Kasumagic-Halilovic E, Prohic A. Nail changes in alopecia areata: Frequency and clinical presentation. J Eur Acad Dermatol Venereol. 2009;23:240-1.

5. Perret C, Wiesner-Menzel L, Happle R. Immunohistochemical analysis of T-cell subsets in the peribulbar and intrabulbar infiltrates of alopecia areata. Acta Derm Venereol (Stockh). 1984;64:26-30.

6. Dubois M, Baumstarck-Barrau K, Gaudy-Marqueste C, Richard MA, Loundou A, Auquier P et al. Quality of life in alopecia areata: A study of 60 Cases. J Invest Dermatol. 2010;130:2830-3.

7. Happle R. Antigenic competition as a therapeutic concept for alopecia areata. Arch Dermatol Res. 1980;267:109-14.

8. Mittal R, Sudha R, Murugan S, Adikrishnan, Shobana S, Anandan S. Pulse Therapy in Dermatology. Sri Ramachandra J Med. 2007;1(2):2007.

9. Adams EM, Yocum DE, Bell CL. Hydroxychloroquine in the treatment of rheumatoid arthritis. Am j med. 1983;75(2):321-6.

10. Stephan F, Habre M, Tomb R. Successful treatment of alopecia totalis with hydroxychloroquine: Report of 2 cases. JAAD. 2013;68(6):1048-9.

11. Urmila B, Sushil P. Scoring systems in dermatology. Indian J Dermatol Venereol Leprol. 2006;72(4):31521.

12. Finlay AY, Khan GK. Dermatology Life Quality Index (DLQI)-a simple practical measure for routine clinical use. Clin Exp Dermatol. 1994;19(3):210-6.

13. Hordinsky M, Kalish R. Plaquenil for Alopecia Totalis. Clinicaltrials.gov. 2009.

14. Duri Yu, Silverberg N, Stein SL. Alopecia areata and Hydroxychloroquine- A review of 8 cases. Pediatrics Dermatol. 2018;35(3):361-5. 
15. Khaitan BK, Mittal R, Verma KK. Extensive alopecia areata treated with betamethasone oral mini-pulse therapy: An open uncontrolled study. Indian J Dermatol Venereol Leprol. 2004;70:350-3.
Cite this article as: Jambusayee J, Sudha KM. A randomised, open label comparative study of hydroxychloroquine with betamethasone oral mini pulse in the management of patients with alopecia areata. Int J Basic Clin Pharmacol 2021;10:187-92. 